\title{
Research Paper \\ A Meta-Analysis of the Effect of Parental Management Training on Behavioral and Emotional Problems in Iranian Children
}

\author{
Ali Isazadegan ${ }^{1}$, Khoshdavi Ebrahimzade ${ }^{* 2}$, Leila Sepas ${ }^{3}$, Fateme Zeynalpour ${ }^{3}$ \\ 1. Professor, Department of Psychology, Faculty of Literature and Humanities, Urmia University, Iran \\ 2. Ph.D. Student of Psychology, Faculty of Literature and Humanities, Urmia University, Iran \\ 3. Ph.D. Student of Psychology, Urmia Branch, Islamic Azad University, Urmia, Iran
}

Citation: Isazadegan A, Ebrahimzade K, Sepas L, Zeynalpour F. A meta-analysis of the effect of parental management training on behavioral and emotional problems in iranian children. Quarterly Journal of Child Mental Health. 2019; 6(3): 78-88.

http://dx.doi.org/10.29252/jcmh.6.3.8

A R T I C L E I N F O

\begin{tabular}{l}
\hline Keywords: \\
Parent management \\
training, \\
behavioral and emotional \\
problems, \\
children
\end{tabular}

Received: 5 May 2018

Accepted: 31 Oct 2018

Available: 9 Nov 2019

\begin{abstract}
A B S T R A C T
Background and Purpose: Childhood disorders have an important impact on the child, peer relationship and family relationship. Different researches indicate that the parents of these children experience higher stress because they deal with more parenting challenges. Therefore, the present research aimed to combine the results of studies conducted on the effectiveness of parent management training on children's behavioral and emotional problems.

Method: The method of this research is meta-analysis. The study population included the available full-text related national studies conducted from 1999 to 2017. Based on inclusion and exclusion criteria, 21 effect sizes were obtained from 17 studies. To analyze the data, sensitivity analysis, funnel chart, fixed and random effects models, and the heterogeneity analysis with CMA software were used.

Results: Data analysis showed that combined effect size for the fixed effects model (model selected for this meta-analysis) was equal to 0.995 which was statistically significant $(\mathrm{P}<0.01)$.

Conclusion: The effect size obtained by parent management training on children's behavioral and emotional problems was calculated according to large Cohen's table and results showed that parent management training was effective on children's behavioral and emotional problems.
\end{abstract} * Corresponding author: Khoshdavi Ebrahimzade, Ph.D. Student of Psychology, Faculty of Literature and Humanities, Urmia University, Iran.
E-mail addresses: Ebrahimzade113@gmail.com 


\section{فراتحليل تأثير آموزش مديريت والدين بر مشكلات رفتارى و هيجانى كود كان ايرانى

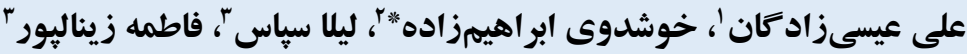

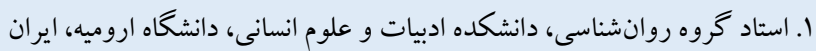

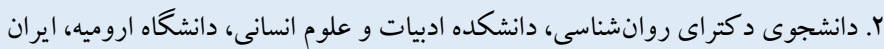

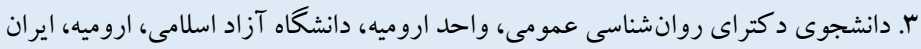

زمينه و هدف: اختلالات دوران كودكى تأثير مهمى بر كودك، روابط با همسـالان، و روابط خانوادكى دارند. نتايج يزوهشهاى مختلف

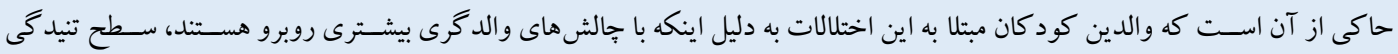

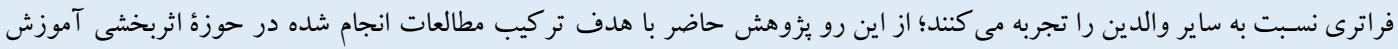
مديريت والدين بر مشكلات رفتارى و هيجانى كو دكان انجام شده است.

جكيده

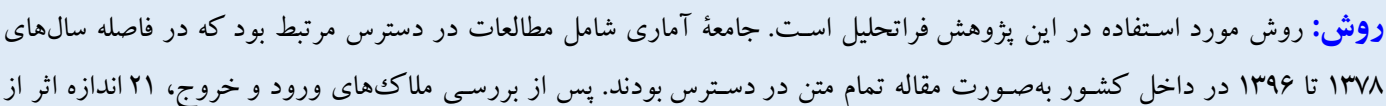

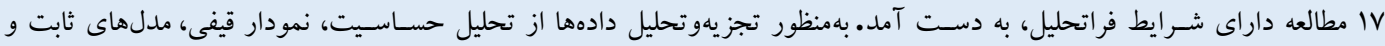

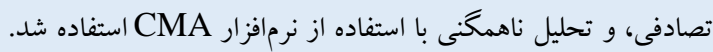

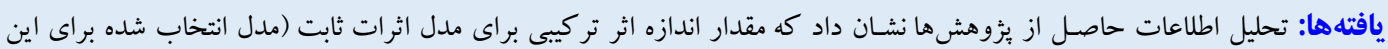

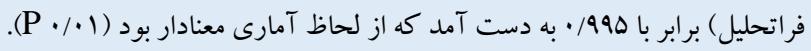
نتيجه كيرى: اندازه اثر بهدســـآمده از روشهاى آموزش مديريت والدين بر مشـكلات رفتارى و هيجانى كود كان طبق جدول تفسـير اندازه كوهن بزرگی، محاسبه شد و نتايج نشان داد كه روشهاى آموزش مديريت والدين بر مشكلات رفتارى و عاطفى كود كان مؤثر بوده
مشخصات مقاله

كليدوازهها:

آموزش مديريت والدين،

مشكلات رفتارى و عاطفى،

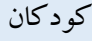

دريافت شده: QV/ P يذير فته شده: Q

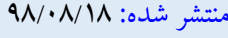

* نويسنده مسئول: خوشدوى ابراهيمزاده، دانشجوى دكتراى روانشناسى، دانشكده ادبيات و علوم انسانى، دانشكاه اروميه، ايران. راياناهם: Ebrahimzade113@gmail.com

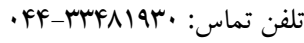


رابطه مطلوب ميان والد و كودك مىتواند ايمنى كود كك را حفظ كند و

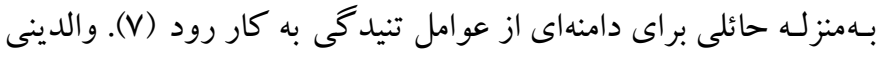

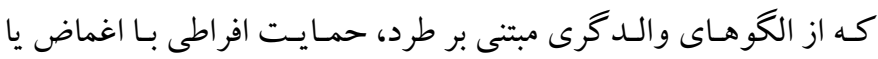

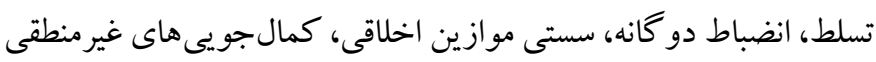

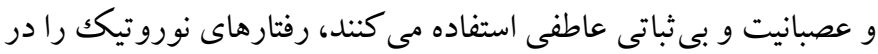

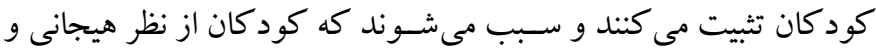
عاطفى نيازمندتر شده و از حسن اعتماد و امنيت كه اساس تحول هيجانى

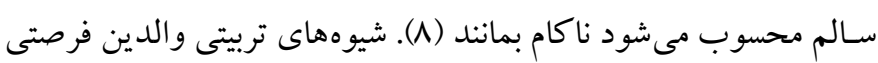

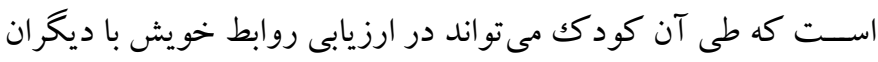
تصويرى مثبت از خويش بيافريند. از سويى ديخر سطح انتظار كودكى از

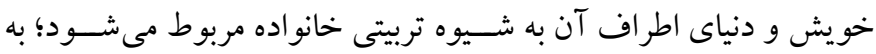

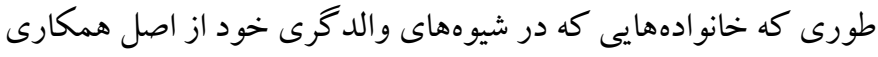

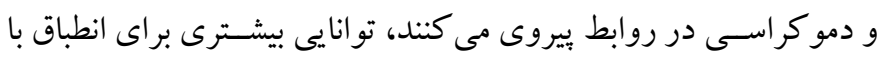
تغييرات دارند و شرايط مناسبى براى تحول كود كان فراهم مى كنند (9).

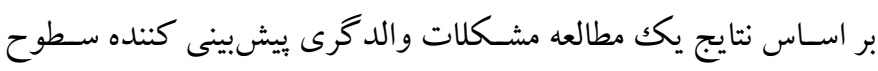
منفى روابط والد -كود كك و مشكلات رفتارى كود كان بوده است ( •1). يكك نوع مداخله روانشــناختى براى مشـكلات بالينى در زمينه

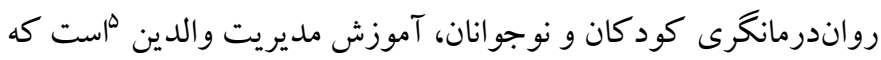
به دليل ويزگ گىهاى منحصربهفرد خود بر ساير روشها برترى دارد (11).

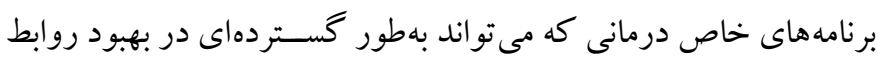
والدين با كودكك به كار روند عبارتاند از: درمان تعامل والد- كودكى كُ

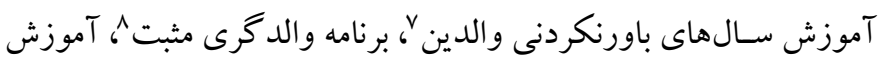

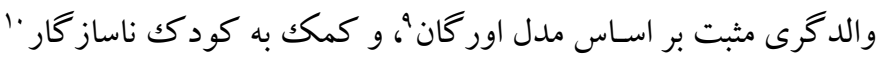

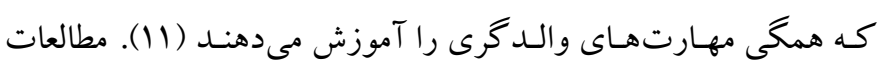

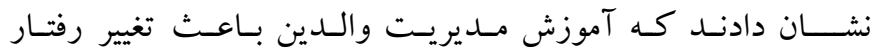
شـناختى_عاطفى بدر و مادر و تغيير متقابل رفتار كودكك شــده اسـت

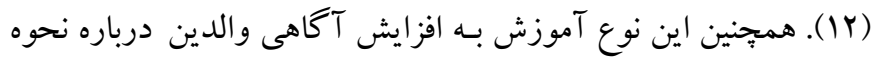

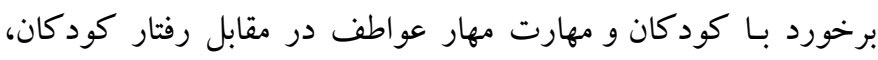

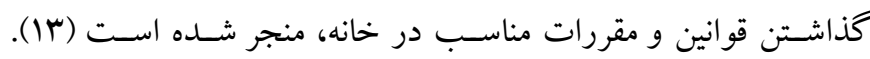

مقلدمه اختلالات رفتارى و هـيجـانى ' شامل گروهى از اختلالات كودكان و نوجوانان است كه بـهـــورت صفات و عادات نامطلوب نظير انخشت مكيدن، شبادرارى، و حمـــلات كج خلقى؛ و يـــا بهصورت اختلالات

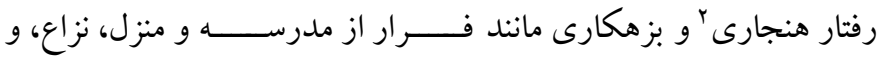
مشاجره؛ و يا بهصورت صفات نوروتيكك خـاص مانند تيكك، اسِاسمهاى عادتى، و خوابكردى؛ و يــا بهصورت مشكلات تحصيلى و مسـائل كلى مربـوط بـه مدرسـه بـروز مى كنند (1). در طبقهبندى ديخرى از مشكلات رفتـارى و عـاطفى كودكان در اصل، اختلالات رفتارى به دو كروه كلى

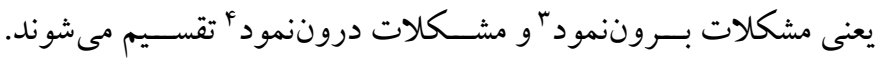
مشـكلات بــرون نمود معطـوف بــه خارج و مشتمل بر رفتارهايى مانند برونريزى، ســـيزهجــــيى، و نافرمانى؛ و مشكلات درون نمود بيشـــتر

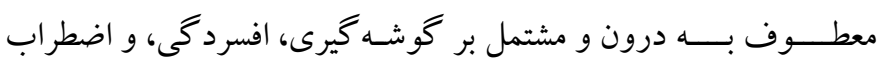

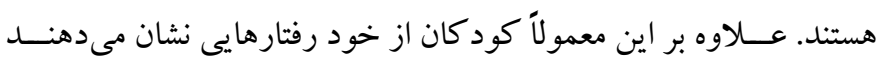
كـه در هـيج يـك از ايـن دو حيطه قـرار نمسى كيـرد (مشـكلات خواب، تغذيه، و مشكلات مربوط به آداب توالت رفتن) (Y). اختلالات دوران كودكى تأثير مهمى بر خود كودكك و خانواده داشته و كار در مدرسـه، روابط با همسـالان، و روابط خانوادگى را تحت تأثير قرار مى دهـد (r). يُزوهش هـا نشــان دادهاند كه والدين كود كان مبتلا به اختلال هاى هيجانى رفتارى به دليل اينكه با جالش هاى و الدكرى بيشترى روبرو هسـتند، تنيدكى فراترى از والدين سـاير كود كان دارند (F). توجه به آنجه در مورد اثرات منفى و غيرقابل اجتناب روش والدگرى ضسعيف بر مشكلات رفتارى كود كان و والدين آنها مطرح است به نظر مىرسد با مداخله در شـيوه والدكرى بهصسورت آموزش و تربيت والدين، مىتوان دركك مهارتهـاى واللدينى و تعامل هاى والد - كودكك را بهبود و ارتقا بخشـيد (ه)؛ رابطهاى كه از يككسو مى تواند كودكى را به انسانى كامل، رشـديافته، و بهنجار تبديل كند و از سـوى ديخر در صورت تخريب اين

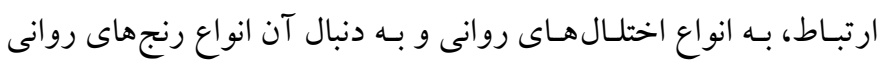

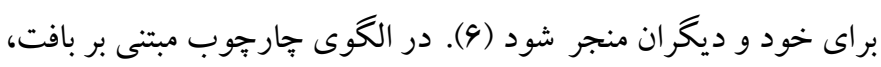

1. Emotional and behavioral disorders

2. Conduct disorder

3. Externalizing

4. Internalizing

5. Parent management training 
جـامعه مـذكور، مقـالاتى كه ملاككهاى ورود به فراتحليل را دارا بودند،

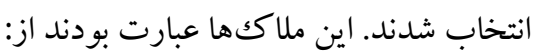

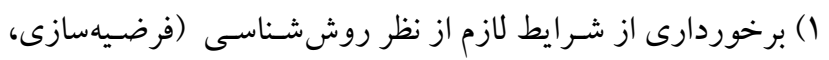

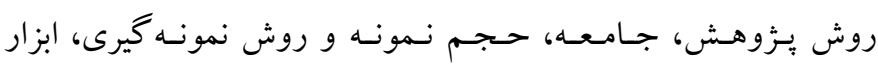

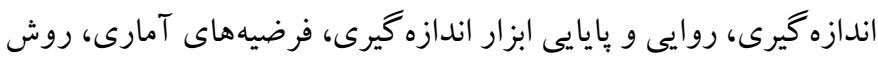

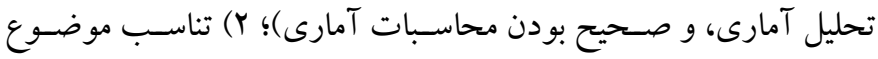

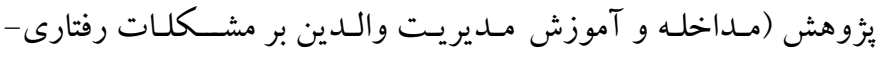

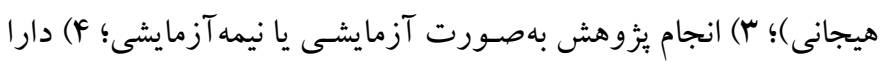

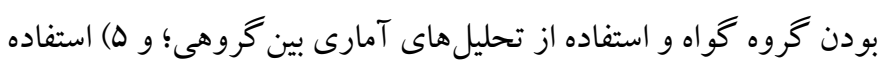
از ابزار يُزوهش مناسـب و يايا جهت سنجش مشكلات رفتارى و هيجانى

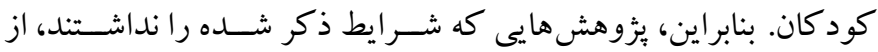

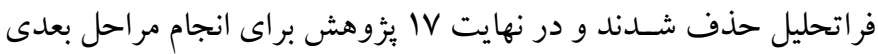

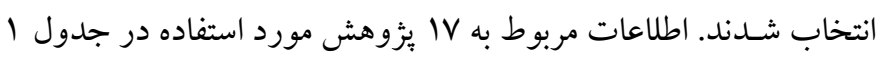
ارائه شده است.

در اين يُزوهش براى جمع آورى اطلاعات از جككليست مشخصات

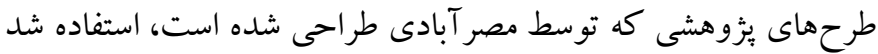

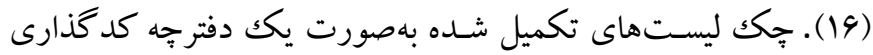

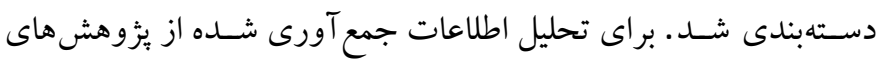

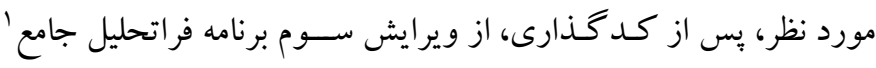

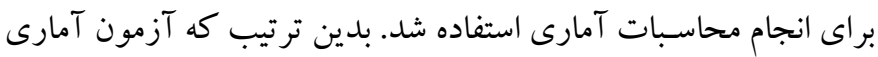
اسـتفاده شــده در فرضسيات، بس از تبديل به اندازه اثر، مورد تحليل قرار

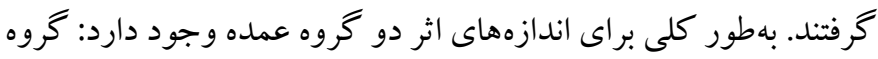

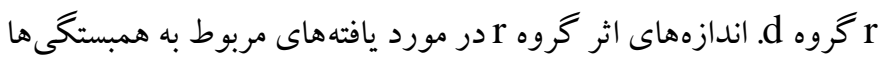

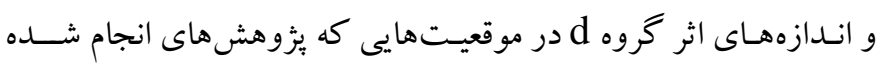
تفاوتها را بررسـى مى كنند، به كار مىروند. كوهن (1991) طبقهبندى تهري كلى تفسيرى براى اهميت نسبى اندازه هاى اثر ارائه داده است كه بر براى

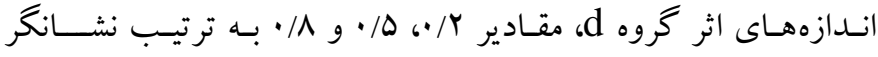

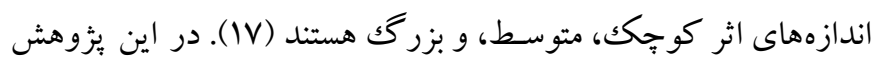
از بين انواع شاخصهاى d از شاخص g هكز استفاده شد.
درمان مديريت والدين در افزايش تعامل همكارى بيشـتر والدين در تربيت كودك،، كاهش خشــم والدين، و همجينين كاهش مشـكلات

هيجانى رفتارى كود كان نقش تعيين كنندهاى داشته است (fأ و ها (1).

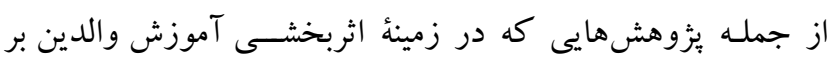

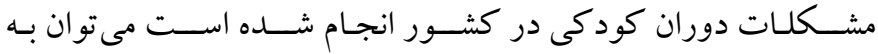

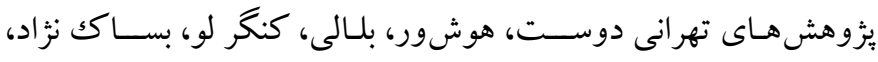

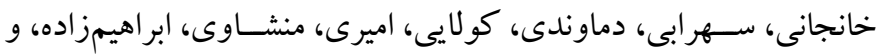

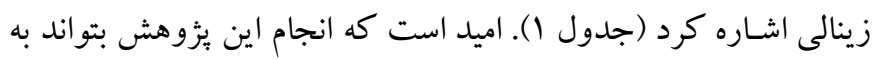

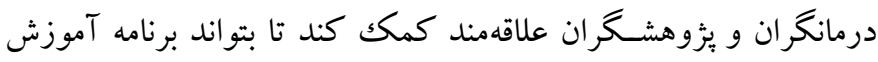
مديريت والدين و اثربخشى آنها را بر كاهش مشكلات رفتارى و هيجانى

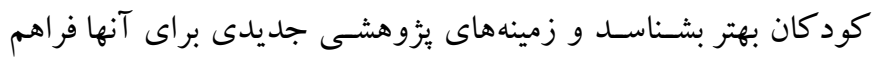

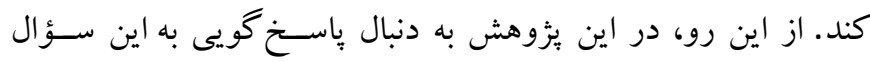

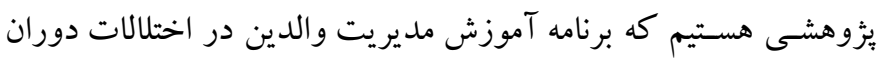

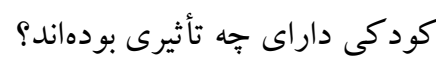
بنابراين، بزوهش حاضـر با هدف مرور مطالعات انجام شـده در

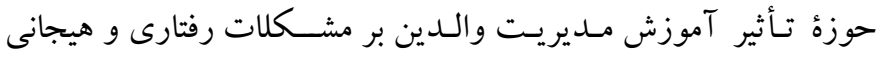

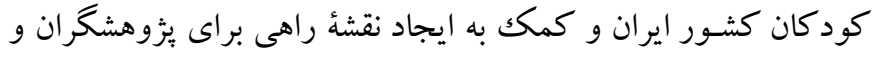

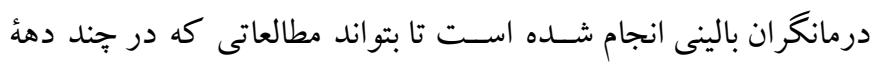
اخير در داخل كشـور در اين حيطه انجام شــده اسـت را توصسيف و جمعبندى كند.

روش در اين يُزوهش با توجه به هدف مورد نظر، از روش فراتحليل استفاده

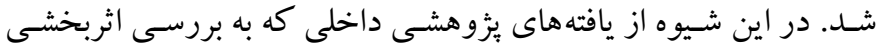

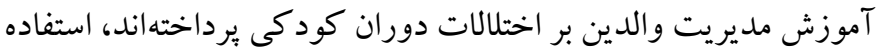

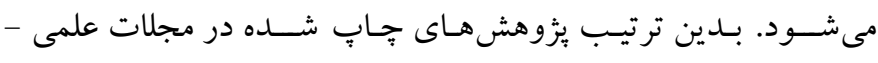

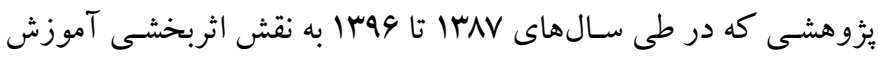

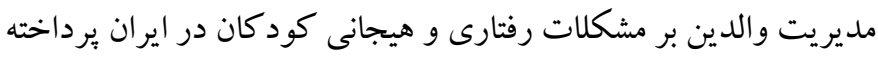

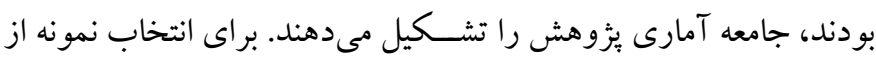


جدول ا: مشخصات نمونه فراتحليل اثربخشى آموزش مديريت والدين بر اختلالات دوران كودكى

\begin{tabular}{|c|c|c|c|c|c|c|c|}
\hline 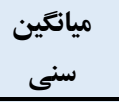 & 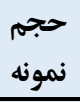 & جلسات & نوع اختلال & سال & يزوهشك & عنوان (كد در منبع) & رديف \\
\hline ساله r r r r & sq & $\wedge$ & مشكلات رفتارى & ITAV & مهدى تهرانى & تأثير آموزش ترييت سازنده فرزندان به والدين در كاهش مشكلات رفتارى & 1 \\
\hline سالد & $\Delta F$ & $\wedge$ & بيشفعالى & IrMA & ي بارسا هوشور & 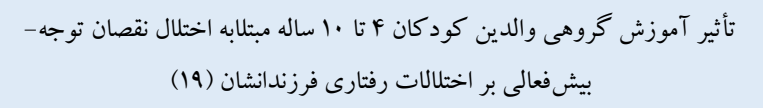 & r \\
\hline ساله 11 & 11 & $\wedge$ & مشكلات رفتارى & irq. & 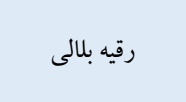 & اثربخشى برنامه آموزش والدين بر كاهش مشكلات رفتارى كود كان ( r) & r \\
\hline 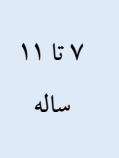 & mr & 1. & بيشفعالى & $|r q|$ & مهناز كنخر لو & 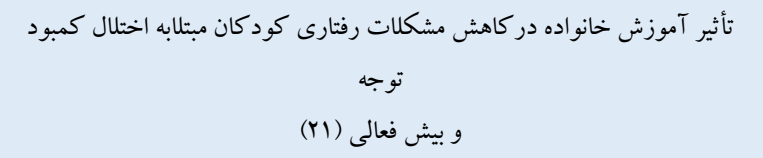 & f \\
\hline ع أ و ساله & $\Delta \cdot$ & 1. & 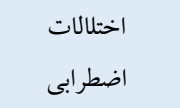 & $|r q|$ & سودابه بساكك نزاد & 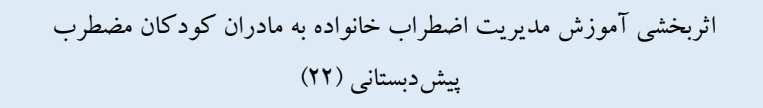 & $\Delta$ \\
\hline 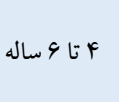 & r. & $\wedge$ & 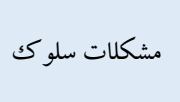 & $|r q|$ & ايران داودى & 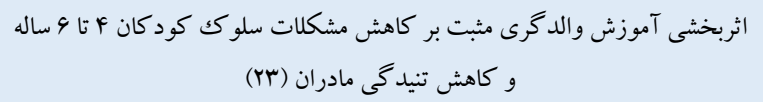 & 4 \\
\hline سالد & $\Delta 9$ & $\Delta$ & بيشفعالى & Irar & 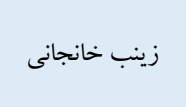 & 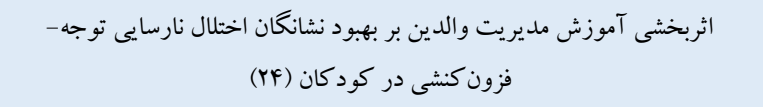 & $\checkmark$ \\
\hline ساله 1111 & $r$. & 9 & 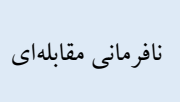 & Irar & 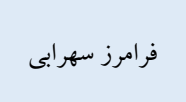 & 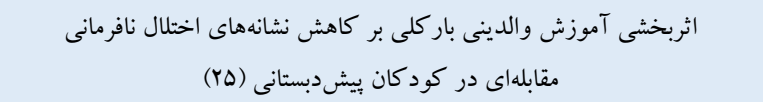 & $\wedge$ \\
\hline ه تام ساله & $r$. & 9 & ع ماطفى -رفتارى & iraf & 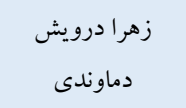 & 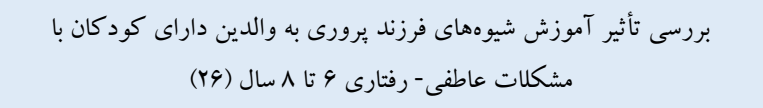 & 9 \\
\hline 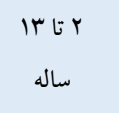 & rr & $\wedge$ & 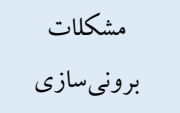 & iraf & 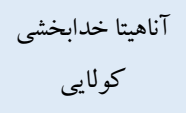 & 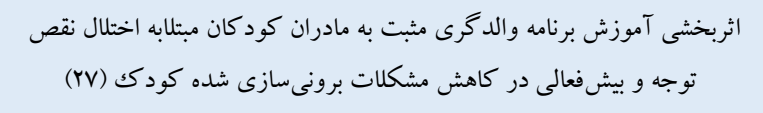 & 1. \\
\hline ساله 9 & rA & 9 & بيشفعالى & iraf & محسن اميرى & 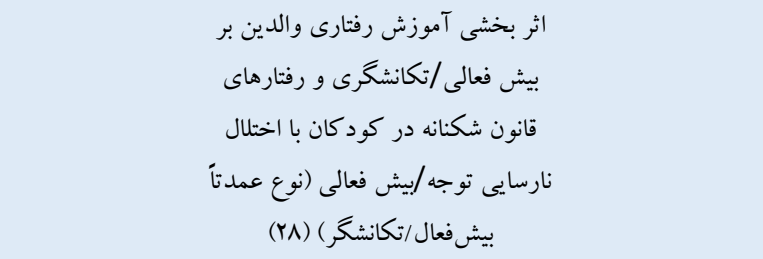 & 11 \\
\hline 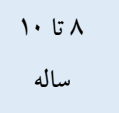 & $r \cdot$ & 9 & نافرمانى مقابلهاى & & مهدى قدرتى & 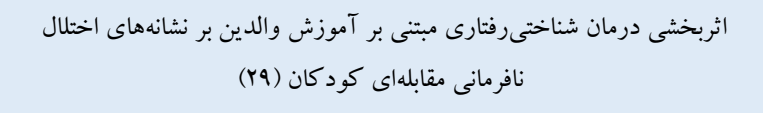 & ir \\
\hline 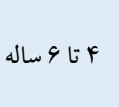 & $\Delta$. & 1. & مشكلات رفتارى & $1 \% 90$ & سيد مسعود دهقان & 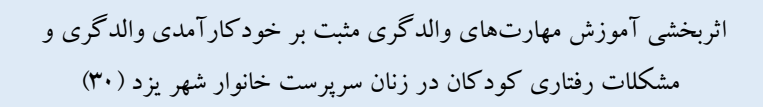 & ir \\
\hline r r r r ساله & re & 9 & مشكلات خوردن & $1 \% 90$ & 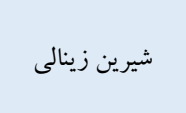 & 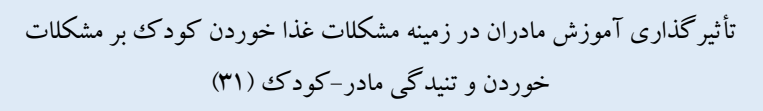 & If \\
\hline 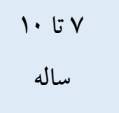 & rq & $\Delta$ & ترس از مدرسه & Irag & خوشدوى & 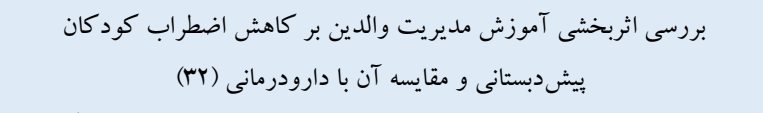 & 10 \\
\hline ساله 9 تا 11 & r. & 9 & نافرمانى مقابلهاى & Iraq & محسن اميرى & 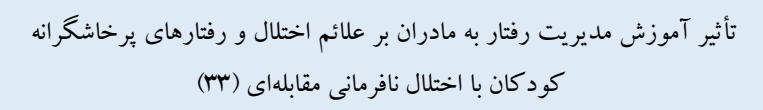 & 19 \\
\hline ع أ تا و ساله & r. & $\wedge$ & 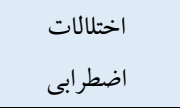 & Iraq & 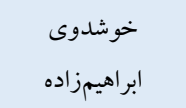 & 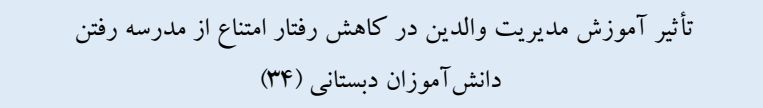 & IV \\
\hline
\end{tabular}


آمارى اثرات ثابت' و اثرات تصـادفى ' هستيند. در مدل اثر ثابت فرض

يافته ها

مىشـود كه يكك اندازه اثر واقعى وجود دارد كه زيربناى همه تحليل ها يس از بررسـى ملاككهاى ورود و خروج، IV مطالعه شــرايط ورود به

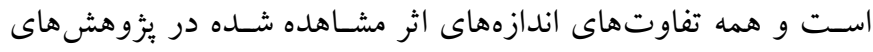

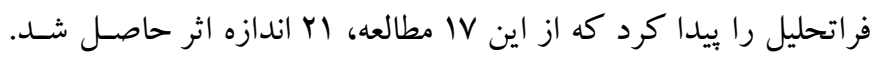

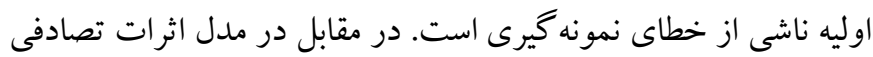

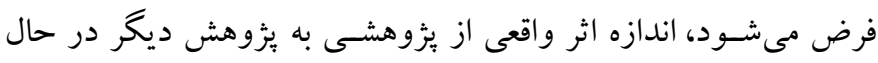

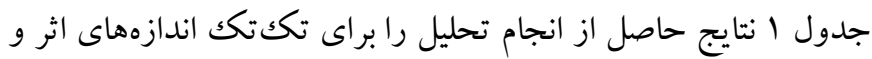

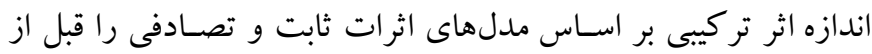
تغيير است. يكى از علل اصلى اين تغيير، وجود متغيرهاى مداخله كنينده

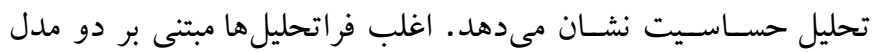

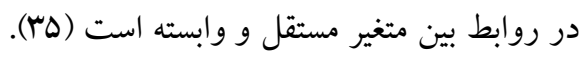

جدول r: اندازه اثرهاى تفكيكى و تر كيبى اثربخشى آموزش مديريت والدين بر اختلالات دوران كودكى

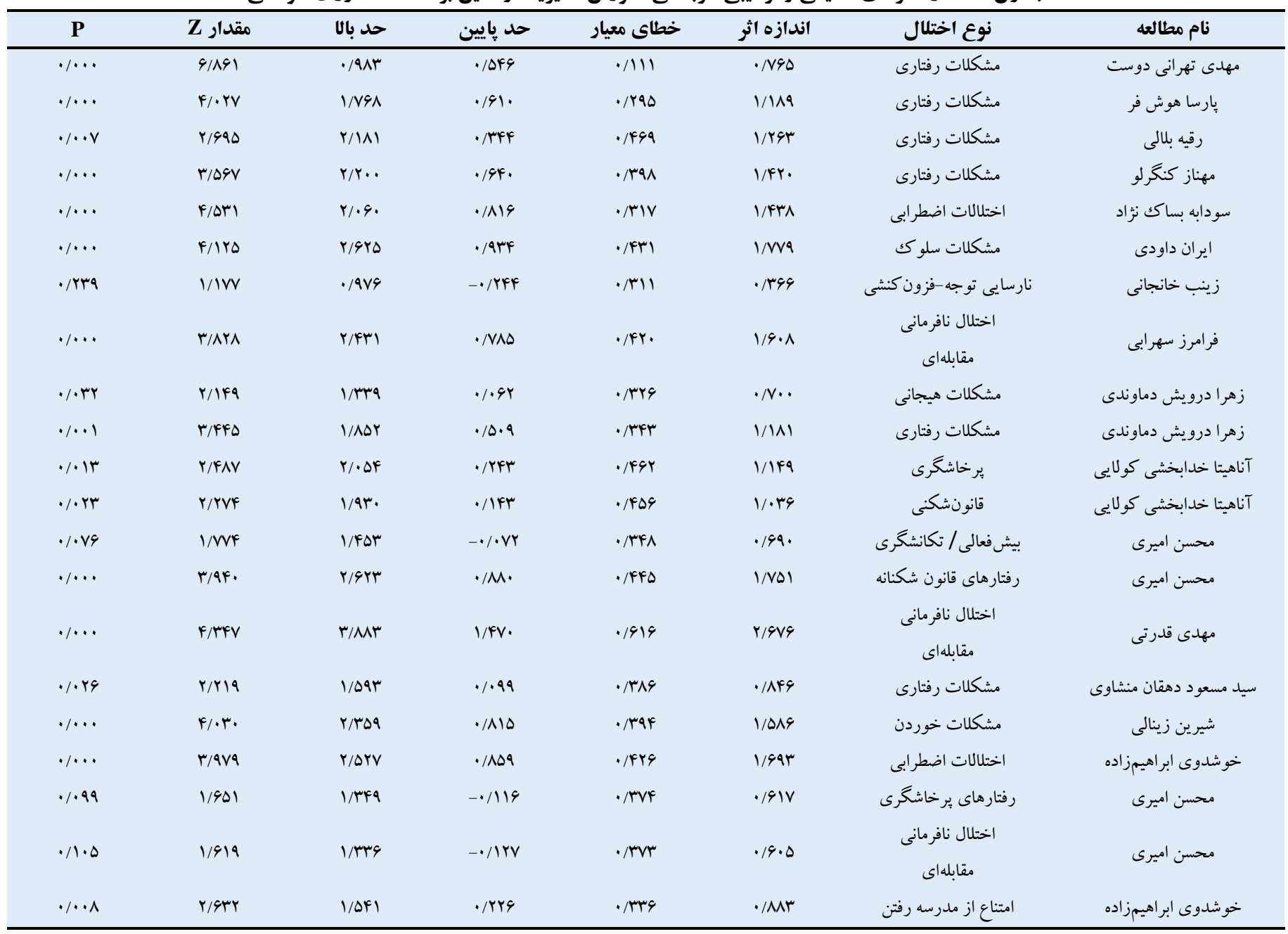

اثر از لحاظ آمارى معنادار هسـتند و f اندازه اثر غيرمعنادار به دسـت آمدهاند.
همانطور كه در جدول r مشـاهده مىشـود، اندازههاى اثر محاسبه

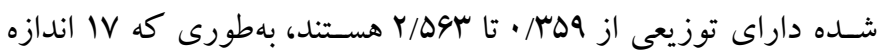

2. Random-effects model

1. Fixed-effects model 
سـو گيرى انتشـار در اندازههاى اثر يثزوهشهاى اوليه برداخته مىشـود. براى بررسى تورش انتشار از نمودار قيفى' و شاخص آمارى تعداد امن از تخريب r استفاده شد.

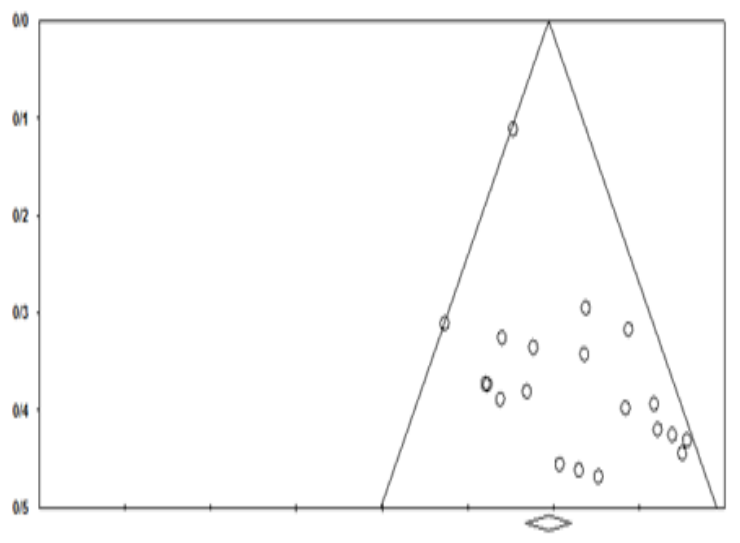

شكل r: نمودار قيفى بعد از تحليل حساسيت
همجينين اندازه اثر تركيبى براى مدل اثرات ثابت برابر با 999/ • و براى مدل اثرات تصـادفى برابر با ها الا، به دسـت آمده اسـت كه بر اساس شاخص كوهن اندازه اثرهاى بزركى هستند (IV). قبل از اينكه بر اسـاس شاخصهاى ناهمكنى، مدل فراتحليل را انتخاب كنيم به بررسى

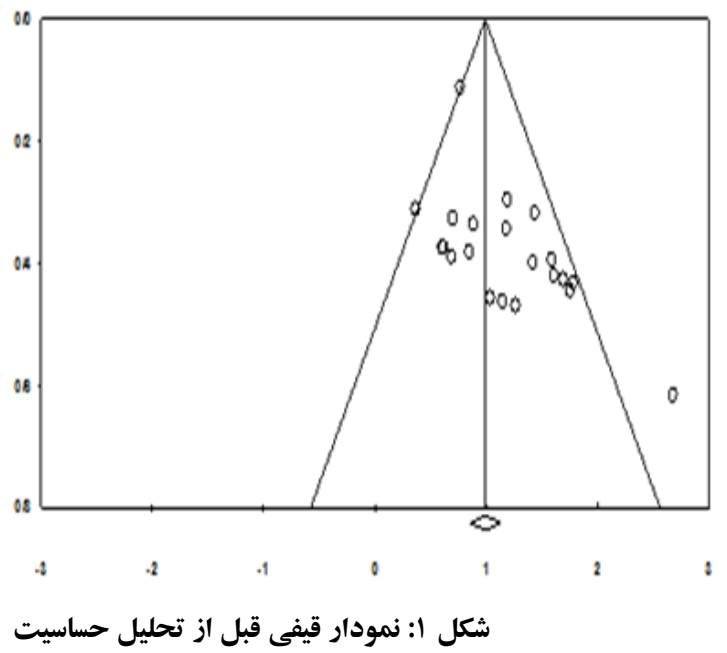

با مشـاهده شـكل و نيز جدول ا مشاهده مىشود كه جند اندازه اثر نامتعارف و يرت وجود دارند كه نمودار را نامتقارن سـاختهاند. اندازه اثر مربوط به مطالعه قدرتى و همكاران كه سوه/Y بهدســتآمده بود، حذف شـــ و دوباره تحليل انجام شـــ. بعد از حذف اين اندازه اثر، نمودار قيفى شكل Y حاصل شد كه نسبت به نمودار شكل ا متقارنتر

جدول بّ: اندازههاى اثر تركيبى مربوط به اثربخشى آموزش مديريت والدين بر اختلالات دوران كودكى بعد از تحليل حساسيت

\begin{tabular}{|c|c|c|c|c|c|c|c|}
\hline \multirow{2}{*}{ PقدارP } & \multirow{2}{*}{ مقدار Z } & \multicolumn{2}{|c|}{ فاصله اطمينان 90٪\% } & \multirow{2}{*}{ خطاى معيار } & \multirow{2}{*}{ اندازه اثر تركيبى } & \multirow{2}{*}{ تعداد اندازه اثر } & \multirow{2}{*}{ مدل } \\
\hline & & حد بالا & حد هايين & & & & \\
\hline$\cdot / \cdots$ & $I F / r V Y$ & $1 / \cdot 19$ & - /AYF & $.1 .9 \mathrm{~V}$ &.$/ 9 \Delta \Delta$ & $r$. & ثابت \\
\hline$\cdot / \cdots$ & $11 / 1 \Delta V$ & $|/ Y Y|$ & $\cdot / \wedge \Delta 9$ & $\% 94$ & $1 / . r 9$ & r. & تصادفى \\
\hline
\end{tabular}

مديريت والدين بر كاهش نشانهاى اختلالات دوران كودكى تأثير مثبتى داشـــه اســت. براى انتخاب بين دو مدل اثرات ثابت و تصــادفى به شاخصهاى ناهمخنى اندازه اثرهاى ئزوهش هاى اوليه مراجعه شد. نتايج مربوط به اين تحليل بر اسـاس دو شـاخص Q كوكران و مجذور I در جدول F انشان داده شده است. 
اندازه اثر اسـت. همجِنين، از اين نمودار مىتوان به تأثير مثبت آموزش والدين بر كاهش نشانهاى اختلالات دوران كودكى يى برد.

\section{بحث و نتيجه كيرى}

يُزوهش حاضر با هدف تركيب مطالعات انجام شده در حوزه اثربخشى دئى

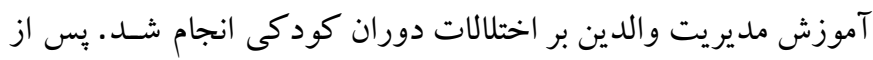

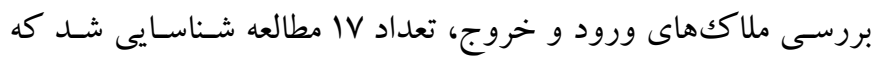
داراى اطلاعات للازم براى محاسـبه اندازه اثر بودند كه از اين تعداد لمداد

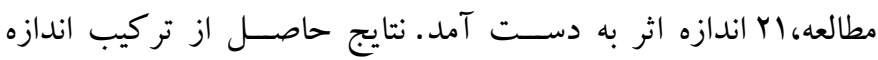
اثرهاى محاسبه شده نشان داد كه آموزش مديريت والدين تأثير مثبت و

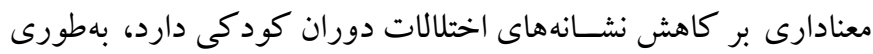

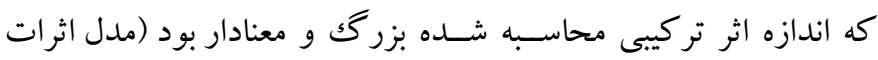

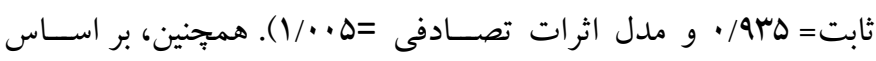
شـاخصهاى ناهمخنى مشـخص شـد كه در بين اندازه اثرهاى مطالعات

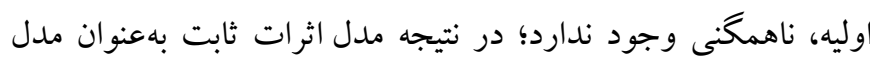
اين فراتحليل انتخاب شد.

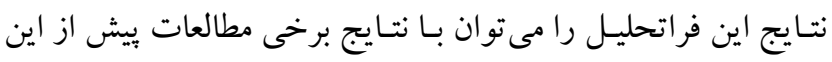

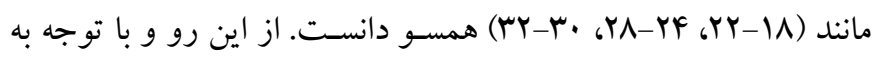
نتايج اين فراتحليل مىتوان بيـان كرد كـه ارتباط والد-كودك در

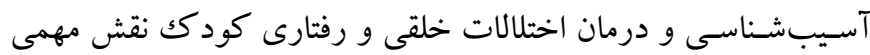

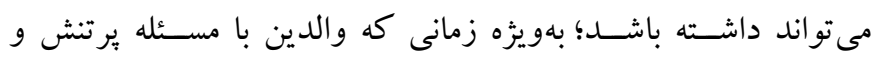

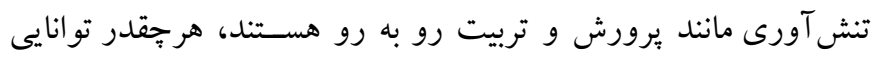

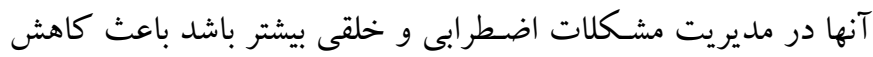

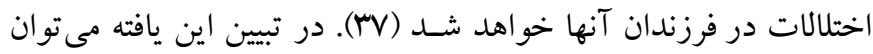

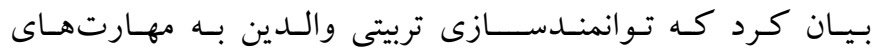
والدينى،آشـنايى آنها با تأثيراتى كه شـيوههاى والدگرى مى تواند بر

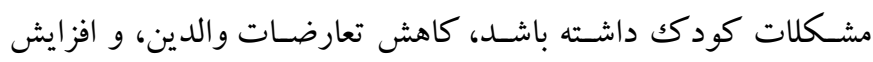

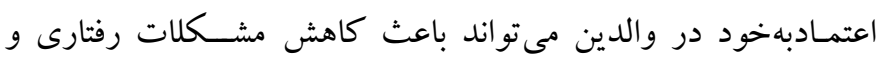

$$
\text { هيجانى در فرزندان شود. }
$$

در تبيين نتايج بهدست آمده همجينين مى توان عنوان كرد كه والدين

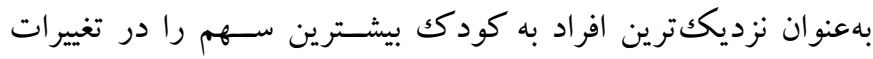

جدول ع: شاخصهاى ناهمغنى اندازههاى اثر در بين ثزوهشهاى اوليه

\begin{tabular}{|c|c|c|c|c|}
\hline I مجذور & معنادارى سطح & آزادى درجه & 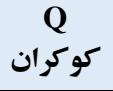 & كنى \\
\hline$M F / F I r$ & .1 .94 & r. & rN/৭9Q & قبل از تحليل حساسيت \\
\hline
\end{tabular}

همان گونه كه مشـاهده مىشـود، مقدار شـاخص Q قبل از تحليل

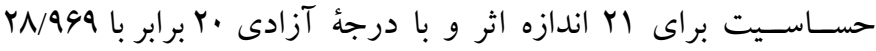
بهدسـت آمده اسـت كه از لحاظ آمارى معنادار نيستــ غيرمعنادارى

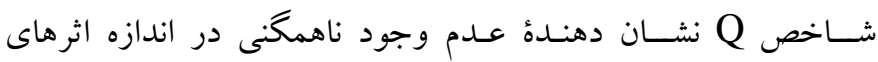
يزّوهشهاى اوليه اسـت. شـاخص ديخرى كه به اين منظور اسـتفاده

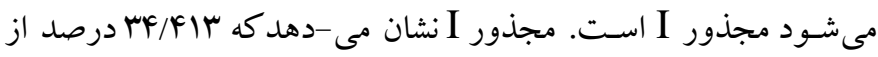
يراكنش موجود در اندازه اثر ئزوهشهاى اوليه، واقعى و ناشسى از

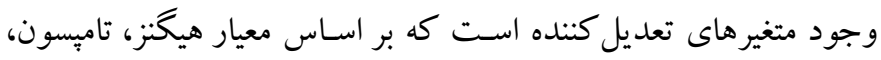

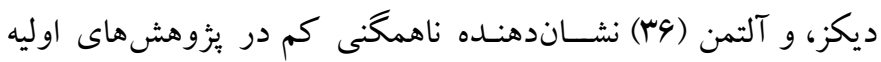

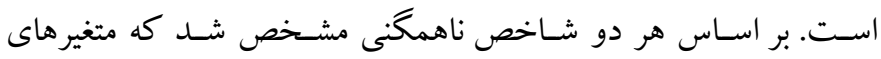
تعديل كننده در اثربخشسى آموزش مديريت والدين بر اختلالات دوران كودكى نقش معنادارى ندارند، بر اين اسـاس مدل ثابت بهعنوان مدل

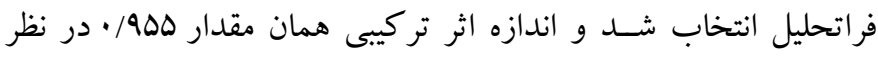

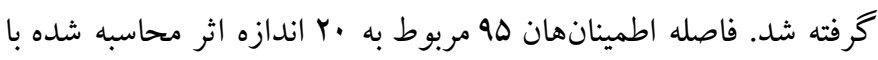
استفاده از نمودار بيشهاى' در شكل با ارائه شده است.

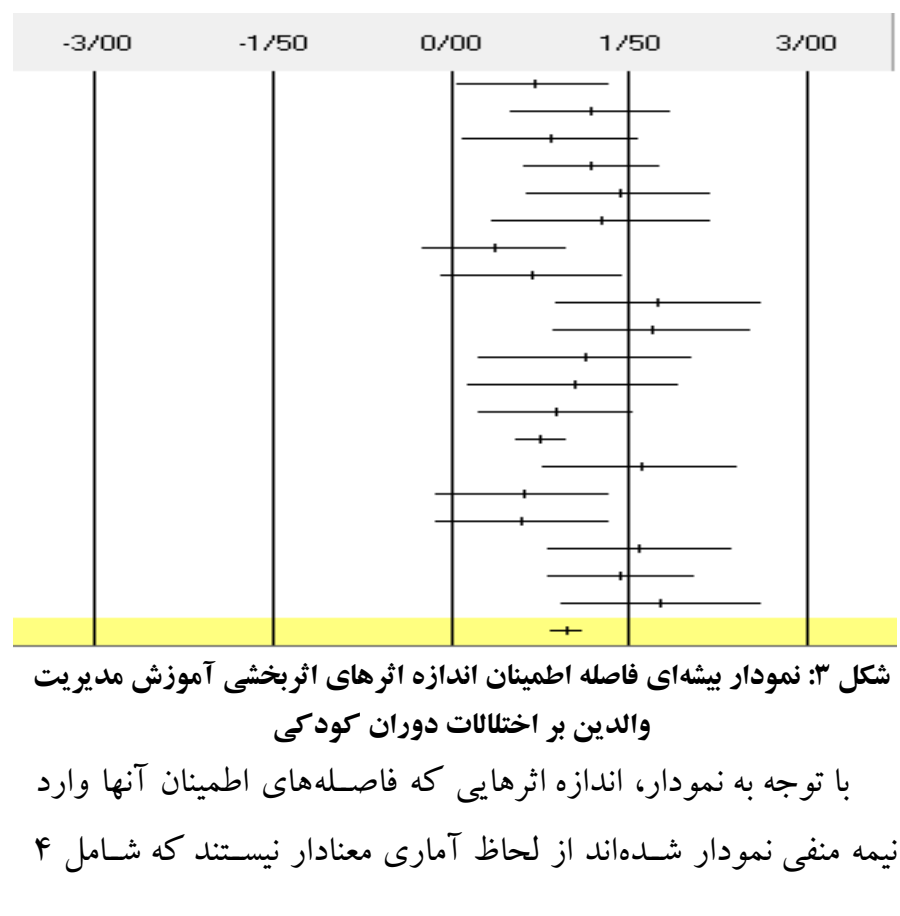

1. Forest plot 
رفتارى همجِون آكاهى والدين از نشانها و علل و روشهاى درمان آن،

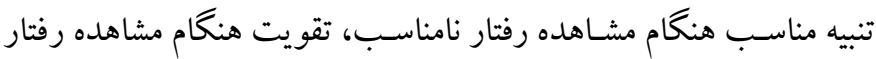

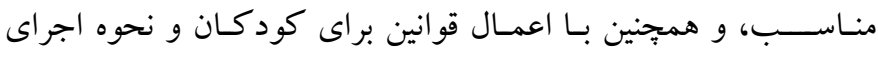
دستورات لازم باعث كاهش مشكلات رفتارى و هيجانى در كود كان شده

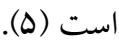

با توجه به نتايج به دسـت آمده به درمانكر ان و يُزوهشـخر ان ويشـنهاد

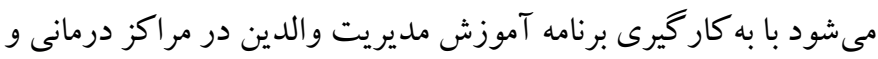

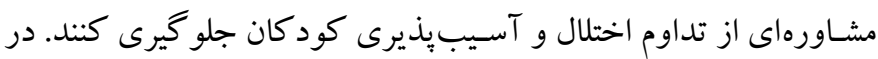

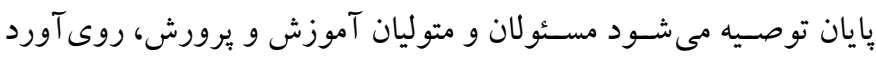

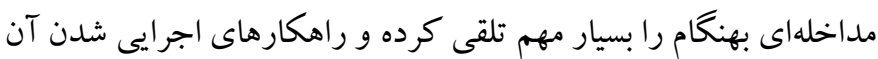

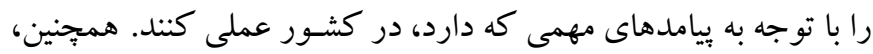

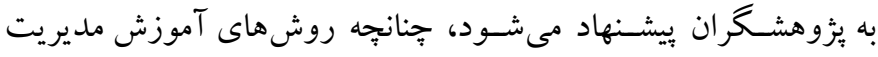

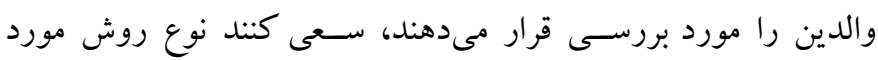

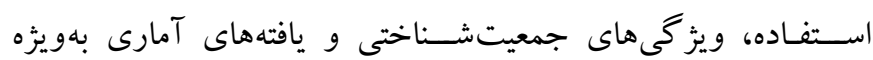

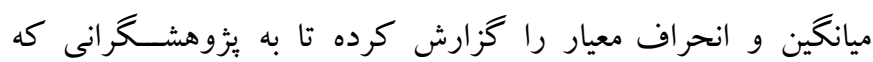
مى خواهند به تركيب و يكيارجهازسى مطالعات ببردازند، كمكى كرده باشند.

اين هزوهش نيز همجيون ديخر يثزوهشها با محدوديتهايى همراه

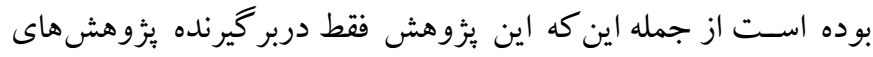
مبتى بر اثربخشى و آموزشهاى انجام شده بر اختلالات كودكان بود

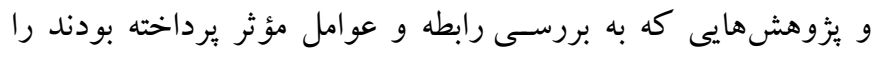

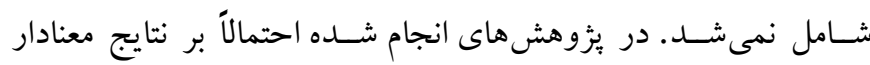

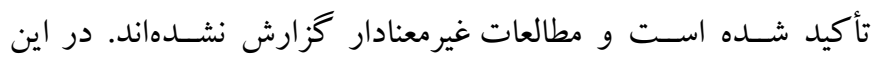

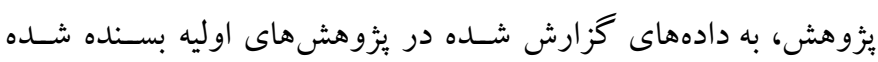

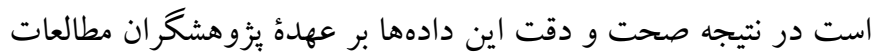

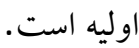

تشكر و قدردانى: :ثزوهش حاضـر يكك مطالعه فراتحليل مستقل است. بدين

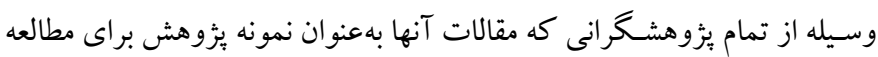
حاضر انتخاب شد، سياسكزارى مىشود.

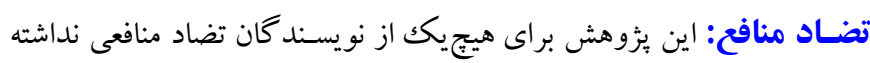

رفتارى او ايفا مى كنند. آموزش مديريت والدين با كاهش فشار و تنش

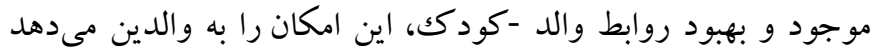

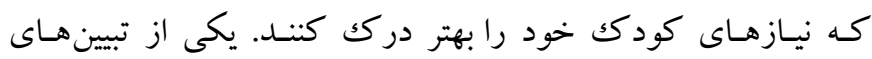

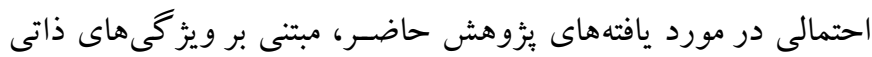

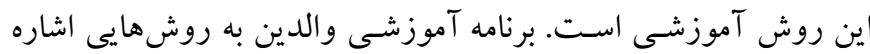
دارد كه به اوليا آموزش داده مىشود تا با كود كان خود بهطور صحيح

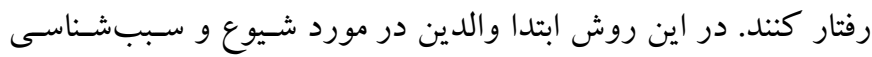

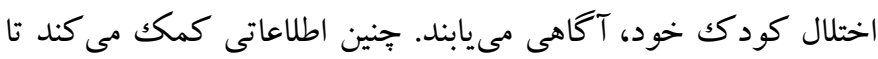

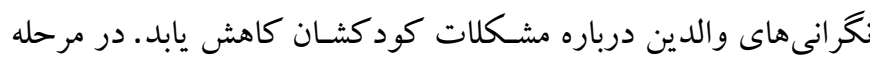

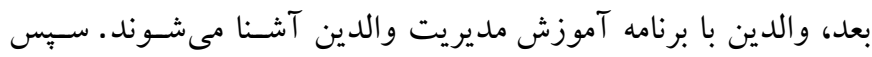

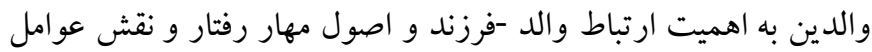

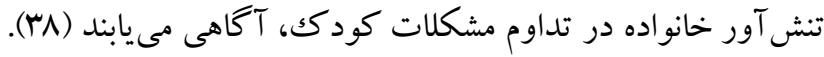
آموزش والدين و آموزش كودكان مى تواند بهعنوان ابزارى مؤثر

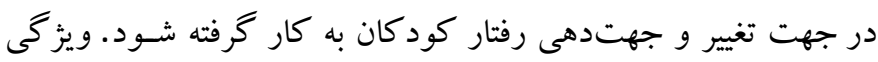
هاى خاص برنامههاى آموزشسى حاضـر، از جمله آموزش شـيوههاى والدگرى و آشــنايى با مشـكلات كودكان مى- تواند مبين تأثيرات

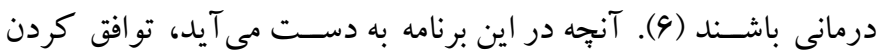

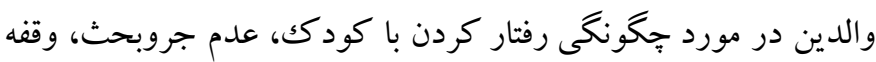

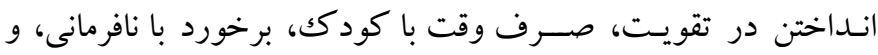

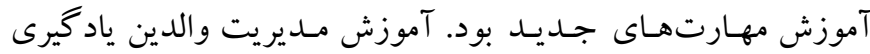

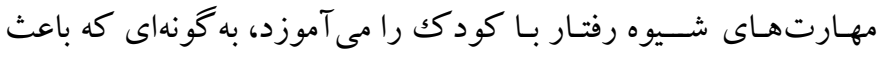
جلو گيرى از رفتارهاى انحر افى، تحول رفتار اجتماعى، و عملكرد انطباقى رونى

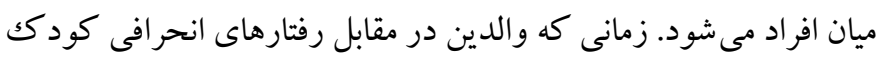

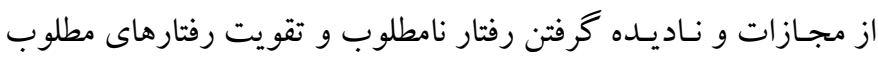

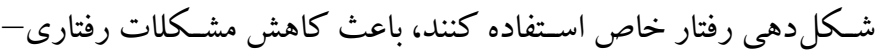

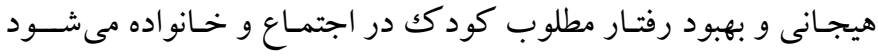

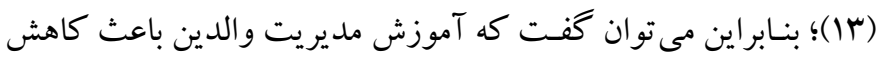

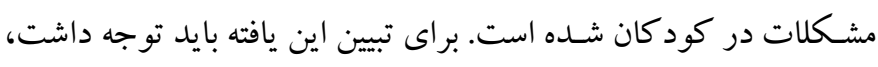

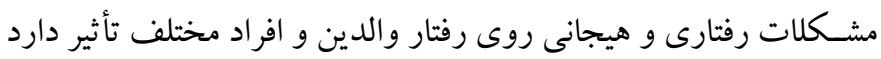

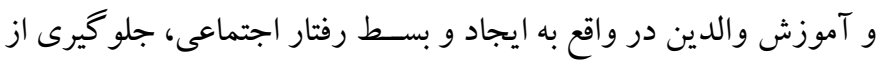

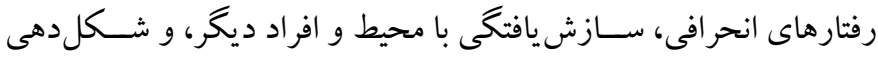
رفتار كودكان مى يردازد (1)). اين آموزش به دليل توجه به به برنامههاى توردي 


\section{References}

1. Sadock BJ, Sadock VA. Kaplan and Sadock's synopsis of psychiatry: behavioral sciences/clinical psychiatry. Lippincott Williams \& Wilkins; 2011, pp: 9-78. [Link]

2. Achenbach TM, Dumenci L, Rescorla LA. Ratings of relations between DSM-IV diagnostic categories and items of the CBCL/6-18, TRF, and YSR. Burlington, VT: University of Vermont; 2001, pp: 1-9. [Link]

3. Coghill D, Soutullo C, d'Aubuisson C, Preuss U, Lindback T, Silverberg M, et al. Impact of attentiondeficit/hyperactivity disorder on the patient and family: results from a European survey. Child Adolesc Psychiatry Ment Health. 2008; 2(1): 31. [Link]

4. Sanders MR. Triple p-positive parenting program as a public health approach to strengthening parenting. J Fam Psychol. 2008; 22(4): 506-517. [Link]

5. Sanders MR, Bor W, Morawska A. Maintenance of treatment gains: a comparison of enhanced, standard, and self-directed triple p-positive parenting program. J Abnorm Child Psychol. 2007; 35(6): 983. [Link]

6. Sanders MR, Kirby JN, Tellegen CL, Day JJ. The triple p-positive parenting program: a systematic review and meta-analysis of a multi-level system of parenting support. Clinical Psychology Review. 2014; 34(4): 337-357. [Link]

7. Grych JH, Harold GT, Miles CJ. A prospective investigation of appraisals as mediators of the link between interparental conflict and child adjustment. Child Dev. 2003; 74(4): 1176-1193. [Link]

8. McCarty CA, Lau AS, Valeri SM, Weisz JR. Parentchild interactions in relation to critical and emotionally overinvolved expressed emotion (EE): is EE a proxy for behavior? J Abnorm Child Psychol. 2004; 32(1): 83-93. [Link]

9. Floyd FJ, Gilliom LA, Costigan CL. Marriage and the parenting alliance: longitudinal prediction of change in parenting perceptions and behaviors. Child Dev. 1998; 69(5): 1461-1479. [Link]

10. Bearss KE, Eyberg S. A test of the parenting alliance theory. Early Educ Dev. 1998; 9(2): 179-185. [Link]

11. Kazdin AE, Whitley M, Marciano PL. Childtherapist and parent-therapist alliance and therapeutic change in the treatment of children referred for oppositional, aggressive, and antisocial behavior. $\mathrm{J}$ Child Psychol Psychiatry. 2006; 47(5): 436-445. [Link]
12. Teti DM, Cole PM. Parenting at risk: new perspectives, new approaches. J Fam Psychol. 2011; 25(5): 625-634. [Link]

13. Forehand R, Lafko N, Parent J, Burt KB. Is parenting the mediator of change in behavioral parent training for externalizing problems of youth? Clin Psychol Rev. 2014; 34(8): 608-619. [Link]

14. Kazdin AE, Glick A, Pope J, Kaptchuk TJ, Lecza B, Carrubba E, et al. Parent management training for conduct problems in children: Enhancing treatment to improve therapeutic change. Int $\mathrm{J}$ Clin Health Psychol. 2018; 18(2): 91-101. [Link]

15. Thijssen J, Vink G, Muris P, de Ruiter C. The effectiveness of parent management trainingOregon model in clinically referred children with externalizing behavior problems in the Netherlands. Child Psychiatry Hum Dev. 2017; 48(1): 136-150. [Link]

16. Mesrabadi J, Faizy A. Meta-analysis of studies on the effectiveness of cooperative learning on academic outcomes of exceptional students. Journal of Exceptional Children. 2015; 15(2): 31-42. [Persian]. [Link]

17. Cohen J. CHAPTER 2 - The $t$ test for means. In: Cohen J, editor. Statistical power analysis for the behavioral sciences. Academic Press; 1977, pp: 1974. [Link]

18. Tehrani-Doost M, Shahrivar Z, Mahmoudi Gharaie J, Alaghband-Rad J. Efficacy of positive parenting on improving children's behavior problems and parenting styles. Iranian Journal of Psychiatry and Clinical Psychology. 2009; 14(4): 371-379. [Persian]. [Link]

19. Houshvar P, Behnia F, Khoushabi K, Mirzaei H, Rahgozar M. Effect of group parent management training on behavioral disorders of children with attention deficit-hyperactivity disorder. Archives of Rehabilitation. 2009; 10(3): 24-30. [Persian]. [Link]

20. Belali R, Aghayosufi AR. Effects of parental training program on the reduction of behavioral problems of children. Journal of Applied Psychology. 2012; 5(4): 59-73. [Persian]. [Link]

21. Kangarlou M, Lotfi Kashani F, Vaziri S. Investigating the effects of parents training on decreasing behavioral problems of children suffering from attention deficit and hyperactivity disorder (ADHD). Medical Science Journal of Islamic Azad Univesity - Tehran Medical Branch. 2012; 22(3): 216-220. [Persian]. [Link]

22. Bassak-Nejad S, Poloi ShaporAbadi F, Davoudi I. Efficacy of family anxiety management training with 
mothers of anxious preschool children. Zahedan Journal of Research in Medical Sciences (Tabib-EShargh). 2014; 16(5): 45-49. [Persian]. [Link]

23. Davoudi I, Basak S, Zarezadegan B. The effectiveness of positive parent training in reducing conduct problems of children and maternal stress of their mothers. Biannual Journal of Applied Counseling. 2012; 2(2): 45-59. [Persian]. [Link]

24. Khanjani Z, Amini S, Malek A, Hashemi T, Amiri S. The effectiveness of parent's management training on improvement of attention deficit hyperactivity disorder syndrome in children. Journal of Developmental Psychology. 2014; 10(39): 311-320. [Persian]. [Link]

25. Sohrabi F, Asadzadeh H, Arabzadeh Z. Effectiveness of Barkley's parental education program in reducing the symptoms of oppositional defiant disorder on preschool children. Journal of School Psychology. 2014; 3(2): 82-103. [Persian]. [Link]

26. Darvish Damavandi Z, Khorsandpur T. The efficacy of training parenting methods to parents of children with emotional-behavioral problems 6 to 8 years. Journal of Education, Counseling and Psychotherapy. 2015; 4(16): 68-81. [Persian]. [Link]

27. Khodabakhshi Koolaee A, Shahi A, Navidian A, Mosalanejad L. The effect of positive parenting program training in mothers of children with attention deficit hyperactivity on reducing children's externalizing behavior problems. Journal of Fundamentals of Mental Health. 2015; 17(3): 135141. [Persian]. [Link]

28. Amiri M. Effectiveness of parent behavioral training on hyperactivity/ impulsivity and rule-breaking behaviors in children with ADHD (hyperactivityimpulsivity domain type). Journal of Research in Psychological Health. 2016; 9(4): 90-101. [Persian]. [Link]

29. Ghodrati M. The effect of parental management training base on cognitive- behavior therapy on children with oppositional defiant disorder. Psychology of Exceptional Individuals. 2015; 5(20): 109-123. [Persian]. [Link]

30. Dehghan Manshadi SM, Gholamrezay S, Ghaznanfari F. The effectiveness of positive parenting skills training on parental self-efficacy and children's behavioral problems in female-headed households in city of Yazd. Quarterly Journal of Social Work. 2016; 5(2): 20-27. [Persian]. [Link]

31. Zeinali S, Mazeheri MA, Sadeghi MS, Jabari M. The relationships of mother's attachment to infant and mothers psychological characteristics to feeding problem in infants. Journal of Developmental Psychology. 2011; 8(29): 55-66. [Persian]. [Link]

32. Ebrahimzade K, Agashteh M, Berenjkar A. The effectiveness of parent management training comparing with drug therapy on reducing anxiety in preschool children. Journal of Pediatric Nursing. 2017; 3(4): 41-48. [Persian]. [Link]

33. Amiri M, Movallali G, Nesaiyan A, Hejazi M, Assady Gandomani R. Effect of behavior management training for mothers with children having ODD symptoms. Archives of Rehabilitation. 2017; 18(2): 84-97. [Persian]. [Link]

34. Ebrahimzade K, Agashteh M, Zeynalpour F, Ashrafzadeh S. Effect of parent management education on reducing school refusal behavior of primary school students. Quarterly Journal of Child Mental Health. 2018; 4(4): 71-80. [Persian]. [Link]

35. Borenstein M, Hedges LV, Higgins JPT, Rothstein HR. A basic introduction to fixed-effect and randomeffects models for meta-analysis. Res Synth Methods. 2010; 1(2): 97-111. [Link]

36. Higgins JPT, Thompson SG, Deeks JJ, Altman DG. Measuring inconsistency in meta-analyses. BMJ. 2003; 327(7414): 557-560. [Link]

37. Wakimizu R, Fujioka H, Iejima A, Miyamoto S. Effectiveness of the group-based positive parenting program with Japanese families raising a child with developmental disabilities: a longitudinal study. J Psychol Abnorm Child. 2014; 3(1): 1-9. [Link]

38. Bayrami M, Abdollahi E, Hashemi nosrat abad T. The effectiveness of parent management training on improvement of attention deficit hyperactivity disorder in children with epilepsy: single subject study. Razi Journal of Medical Sciences. 2017; 24(157): 90-98. [Persian]. [Link] 